\title{
APRESENTACุÃO
}

\section{ENTRE EXCESSOS E ESQUECIMENTOS: QUESTÕES CONTEMPORÂNEAS SOBRE A MEMÓRIA}

\author{
Maria Leticia Mazzucchi Ferreira \\ Luis Carlos Toro Tamayo
}

(orgs.)

O dossiê que ora apresentamos comporta uma pluralidade de objetos de reflexão, provindos de autores de diferentes lugares epistemológicos e geográficos. Essa diversidade de abordagens e contextos distintos transforma esse conjunto de textos em um universo plural, tendo como fio condutor a memória em suas mais diferentes abordagens.

No ano em que a obra Memória Coletiva de Maurice Halbwachs completa 70 anos de sua primeira edição, composta por textos escritos entre 1925 e 1944 e compilados, de forma bastante personalizada e como uma espécie de testamento ao futuro, por sua irmã Jeanne Halbwachs (BECKER, 2003), vivemos uma dramática experiência coletiva, inédita na forma como vem se apresentando até o momento. Neste tempo de pandemia, rupturas no cotidiano como o isolamento social, a quarentena, formas reguladoras da convivência social e interdições a rituais fundamentais relativos à morte e ao luto, somos levados a pensar sobre uma transnacionalização de vivências traumáticas, das quais não sabemos quais serão convertidas em memória coletiva.

Contemporâneos, portanto, a uma memória que se processa desde agora, no momento mesmo em que vivemos o presente da pandemia do COVID-19, nos perguntamos como chegará o futuro e quais elementos poderão se inscrever em uma narrativa memorial (PESCHANSKI, 2020). Na perspectiva da memória como princípio da coesão social proposta por Halbwachs, como podemos imaginar a construção da identidade de grupos sociais fundada num presente que todavia resiste a se converter em passado? Ainda, se nos remetemos à noção de memória como o "presente do passado" ou a "presença da ausência" como sublinha Paul Ricoeur (2000), como podemos imaginar a representação deste presente pandêmico? Com quais linguagens e dispositivos construiremos a memória pública de nosso presente?

Os processos de gestão visível do passado no presente nos remetem a diversos registros e linguagens como museus, comemorações, literatura, políticas de memória, elementos que podem ser compreendidos como "vetores de memória" (LAVABRE, 2020) ou sociotransmissores (CANDAU, 2011), em analogia aos mecanismos de formação, obliteração ou mesmo supressão pelo prisma da bioquímica da memória.

É, portanto, na busca de discutir os processos memoriais em suas diferentes expressões, que organizamos este número da Revista Caderno de Letras, que traz como texto de abertura o artigo do antropólogo Joël Candau, o qual nos remete a uma ontologia da memória, problematizando o fato de que, ao abordarmos a questão sobre nossas origens, somos afetados por uma conformação cognitiva grupal que nos induz a adotar um discurso mais metamemorial 
do que memorial, o que explicaria porque identidades que se fundamentam em construções imaginadas, se sobrepõem aos fundamentos de nossa identidade imanente. Nesse sentido, a configuração de uma retórica metamemorial (tão largamente presente nos discursos e disputas identitárias) se sobrepõe a uma memória real, levando-nos a pensar que, se nessa perspectiva a memória agencia exclusões e seccionamentos, como poderíamos convertê-la em mais inclusiva?

Os demais artigos estão organizados formalmente em quatro seções, estas correspondentes a formas estruturantes da formação e narrativa memorial: o dispositivo museológico, a arte, literatura e narrativas biográficas como diferentes linguagens e vetores memoriais.

No plano museal, o artigo de Philippe Mesnard nos leva a uma reflexão importante sobre os museus de memória ou sítios memoriais, espaços destinados a uma representação sempre problemática de processos históricos que impactaram comunidades ou sociedades. Analisando sob a perspectiva do visitante, cada vez mais destituído do papel de meros consumidores culturais e convidados a participar de forma interativa e imersiva no universo museológico, chamado a identificar-se com o que é narrado, Mesnard, através do recurso a três categorias heurísticas (Homotopias, Normotopias e Heterotopias) nos leva a observar estes espaços museológicos em diálogo com o espaço no qual estão inseridos, regulados por formas representacionais da memória que se apresentam como transnacionais e em busca de homogeneização, demarcados pelo viés da empresa turística ou, na perspectiva heterotópica, combinando, aleatoriamente ou não, diferentes matrizes memoriais.

$\mathrm{Na}$ mesma perspectiva de uma análise do espaço museal para além de suas formas visíveis, o artigo de Luis Carlos Toro Tamayo, Verónica Mejía Acevedo e María Cristina Paton lança luz sobre as formas classificatórias e organizacionais das coleções no interior do Museo Casa de la Memoria na cidade colombiana de Medellín. Partindo de uma visão "de dentro", ou seja, com a ênfase conferida à expertise museal, os autores atribuem ao ato de conservar, ato fundador da operação museológica e arquivística, uma função de resistência e resiliência das memórias associadas ao conflito armado na Colômbia contemporânea.

A segunda seção tem como fio condutor a expressão artística envolvendo as dimensões plásticas e dramatúrgicas. Nesse sentido, o artigo de Emmanuelle Sinardet tem como objeto as obras da artista plástica colombiana Érika Diettes que abordam o conflito armado em seu país, expondo uma vigorosa forma de quadros performativos e complementares da memóriamemórias de vitimas subalternas, memórias sensíveis e memórias reparadoras, através de dispositivos artísticos para pensar a relação entre memória e arte.

Já o artigo de Daniel López Ruiz aponta para dramaturgia madrilenha, em particular a de Juan Mayorga, que se compromete a uma expressão teatral que busque a formação de uma memória social. Analisando dois textos do autor, amplia a ideia do fazer teatral como representação memorial de um passado traumático e, ao mesmo tempo, uma memória de si próprio como linguagem dramatúrgica ela própria construindo sua própria memória. Como expressão na interface entre técnica e estética, entre o real e a imaginação, Maria Thereza Gomes de Figueiredo Soares, José Ferreira Junior e Márcia Manir Miguel Feitosa apresentam a fotografia e a poesia, tendo como objeto de análise o Poema Sujo, obra de Ferreira Gullar e três conjuntos de fotografias da série Visões de um Poema Sujo, de Márcio Vasconcelos. Ambos, o poeta e o artista, traduzem, com linguagens diferentes, uma cidade- São Luiz do Maranhãofrente a qual são agenciados e agenciadores de uma memória da cidade e suas articulações com o simbólico.

Também o artigo de Cristina Patricia Sosa propõe uma análise da obra los ojos no quieren estar siempre cerrados do artista espanhol Marcelo Expósito, buscando aborda-la como arte da memória. Arquivos mutantes, tal como definidos pelo artista, apresentam montagens de imagens 
de naturezas e temporalidades diferentes, propondo abordar a experiência como forma de ativar a memória e, ao mesmo tempo, denunciar a política de invisibilidade operada pela imagem dentro da trama social.

A terceira seção apresenta a literatura em sua potência agenciando memórias traumáticas em contextos políticas e culturais de pós-ditaduras. Já o artigo de Cecilia María Teresa López Badano e Linet Cums Yumar aponta para uma discussão ampliada de análise da produção literária pós-ditaduras no Cone Sul, apontando para recorrências e particularidades no modelo narrativo sobre o trauma. Este tema segue no texto de Valéria Gomes Ignácio da Silva, que tem como objeto as experiências da violência e trauma vividos nos períodos ditatoriais do Brasil, Chile e Argentina, retratados em produções literárias caracterizadas como pós-memória e nas quais testemunho e memória são eixos de articulação destas obras. Também o texto de Estefânia Luján Di Meglio aponta para uma análise de textos literários referentes à última ditadura militar na Argentina na perspectiva de testemunhos envoltos em relatos memoriais que vão do individual ao coletivo, externalizando formas de representar o traumático. $\mathrm{O}$ artigo de Maria José Schamun nos remete à literatura, nesse caso a obra Los Pichiciegos de Rodolfo Fogwill, como uma forma de conferir visibilidade frente à política de invisibilização dos corpos relacionados à guerra das Malvinas. $O$ artigo propõe abordar a literatura como uma forma de operar a memória de um passado destinado ao silêncio e ao desprovimento de elementos para se constituir em uma memória coletiva. Da mesma forma, o artigo de Carla Moura Barreto e Tatiana da Silva Capaverde aborda o romance autoficcional O espirito dos meus pais continua a subir na chuva, de Patrício Pron, como forma de pensar as relações entre memória, pós-memória, esquecimento, obra ficcional e caráter arquivístico da obra, relativas ao passado recente argentino, conferindo ênfase ao papel de testemunhos e narradores dos personagens. No artigo de André Winter Noble o centro é a obra O que os cegos estão sonhando? de autoria de Noemi Jaffe, que aborda a memória da Shoah (avó, mãe e filha) na perspectiva de memórias construídas em quadros geracionais e, tal como na perspectiva da pósmemória, as aproximações que gerações distantes do fato gerador apresentam com o mesmo.

Também numa perspectiva de narrativas traumáticas, o artigo de Felipe Adrián Rios Baeza analisa as obras dos escritores Alejandro Zambra e Nona Fernández cujos núcleos temáticos são a memória da infância no Chile sob a ditadura de Augusto Pinochet, partindo de um lugar de produção e enunciação, a escola. Já Óscar Daniel Clavijo Tavera aborda a poesia contemporânea da violência na Colômbia, que tem o silêncio como objeto de reflexão de uma poética da violência (real e simbólica) na qual a palavra impedida é central. Igualmente a narrativa, no caso a narrativa documental, na obra Oración. Carta a Vicki y otras elegías política, é a base de reflexão do texto de Anabel Tellechea.

Na quarta seção deste dossiê a forma de constituição da narrativa se apresenta como elemento organizador. $\mathrm{O}$ artigo de Adriana Minardi tem como centro as relações tensionadas entre memória, história e política nos textos autobiográficos produzidos a partir de 1975 numa Espanha em processo de transição democrática. Também nessa perspectiva está o texto de Ludmila da Silva Catela e Eugenio Talbot Wright abordando a construção memorial a partir da constituição de um relato quase oficial do pós-ditadura, de memórias dissidentes associadas à comunidade "homossexual" representativa dos anos 1960 e a perspectiva de memórias silenciadas que se convertem em memórias insurgentes LGBT na Argentina contemporânea.

$\mathrm{O}$ artigo de Florian Homann traz um estudo de narratologia baseado nas obras de dois autores colombianos: Cien años de Soledad de García Márquez e La Oculta de Héctor Abad, nas quais se verifica de um lado a construção memorial configurada no discurso mítico e distante (o monumental), e de outro a experiência vivida de um passado recente (a experiência).

O artigo de Rejane Fiepke Carpenedo e Eliana Rosa Sturza nos traz um estudo sobre a 
expressão religiosa como lugar de enunciação e cristalização da memória da língua de imigração alemã em um município do interior do Rio Grande do Sul. Também apontando para novas abordagens memoriais está o texto de Paula Daniele Pavan que tem como objeto de reflexão os níveis e processos de formação de estruturas memoriais no universo das redes de internet.

Ressalte-se que estas quatro seções comunicam-se entre si e guardam reflexões que, embora distintas em seus objetos e universos de produção, nos remetem à ideia de sentidos plurais da memória, sentidos que transitam entre esquecimento, silêncios, insurgências e libertação.

\section{Referências:}

BECKER, Annette. Maurice Halbwachs: un intellectuel en guerres mondiales 1914-1945. Paris, Agnès Viénot Éditions, 2003.

CANDAU, Joël. Memória e Identidade. São Paulo, Contexto, 2011.

LAVABRE, Marie-Claire. La mémoire collective comme métaphore. Mélanges de la Casa de Velázquez.2020(online)http://journals.openedition.org/mcv/12894

PESCHANSKI, Dennis. Tu crois qu'on s'en souviendra ? Mémoire collective du Covid-19.Rev Neuropsychol, 12 (2) , 2020: 128-31.

RICOEUR, Paul. La mémoire, l'histoire, l'oubli. Paris, Le Seuil, 2000. 